\title{
Na sequência da tragédia: sofrimento e a vida após o incêndio da Boate Kiss
}

\author{
After the tragedy: life and suffering following the Kiss \\ Nightclub fire
}

\section{Ceres Victora}

Professora titular do Departamento de Antropologia e do Programa de Pós-Graduação em Antropologia Social da Universidade Federal do Rio Grande do Sul. Vinculada ao Núcleo de Pesquisas em Antropologia do Corpo e da Saúde - NUPACS. Possui graduação em Ciências Sociais pela Universidade Federal do Rio Grande do Sul (1982), mestrado em Antropologia Social pela Universidade Federal do Rio Grande do Sul (1991), doutorado em Antropologia na Brunel University (1996) e pós-doutorado na Johns Hopkins University (2011). Tem experiência na área de Antropologia da Saúde, atuando principalmente nos seguintes temas: corpo, gênero, saúde, sofrimento social e ética.

\section{Monalisa Dias de Siqueira}

Pós-Doutoranda no Programa de Pós-Graduação em Ciências Sociais (PPGCS/UFSM). Professora do Departamento de Ciências Sociais - UFSM.

\section{Resumo}

Este artigo visa refletir sobre desdobramentos pessoais e coletivos daquilo que ficou conhecido como a "tragédia de Santa Maria" e sobre "o que está em jogo" para aqueles que tiveram suas vidas profundamente afetadas pelo incêndio da boate Kiss. Para tanto, realizamos pesquisa etnográfica que envolveu observação participante de manifestações públicas relacionadas ao ocorrido; entrevistas e acompanhamento de pais de jovens que padeceram no incêndio; e coleta de dados divulgados em jornais e mídias sociais. Analisamos dois espaços sociais de reconstrução do mundo: (1) o movimento político, em que a "luta por justiça" e pela "punição dos culpados" pela tragédia se apresentaram como veículos de reorganização da vida daqueles que hoje convivem com o luto; (2) a espiritualidade, mais especificamente a doutrina espírita kardecista, na qual os significados, a relação com o evento e com outros agentes envolvidos são modelados pelos diferentes planos de existência humana e espiritual.

Palavras-chave: Sofrimento, Tragédia de Santa Maria, Espiritualidade, Kardecismo, Boate Kiss. 


\section{Abstract:}

This paper examines the personal and collective developments of what has become known as the "Tragedy of Santa Maria" and 'what is at stake' for those whose lives were deeply affected by the Kiss nightclub fire. To that end, we carried out an ethnographic research comprising participant observation of public events related to the fire; interviews and follow-ups with parents of young people who died in the fire; and collection of information from newspapers and social media. We analyzed two social spaces of world reconstruction after that critical event. First, the political movement, in which the "quest for justice" and for the "punishment of the guilty" for causing the tragedy have been ways of reorganizing the lives of the bereft. Second, the spirituality of Kardecist orientation, in which the meanings and the relation with the event and other agents are modeled by the different worlds of human and spiritual existence.

Keywords: Suffering, Tragedy of Santa Maria, Kiss nightclub fire, Spirituality, Kardecism.

\section{INTRODUÇÃO}

O incêndio da boate Kiss ocorrido na madrugada de 27 de janeiro de 2013 em Santa Maria - uma cidade de aproximadamente 300 mil habitantes na região central do estado do Rio Grande do Sul, Brasil - matou 242 pessoas e contou com cerca de 680 sobreviventes, entre jovens universitários e funcionários do estabelecimento. O acontecimento, que ficou conhecido como "A tragédia de Santa Maria”, foi noticiado amplamente por veículos de comunicação do mundo inteiro e abalou de forma dramática a vida daquela cidade.

Vale lembrar, a título de contextualização, que Santa Maria é um importante polo universitário no interior do Rio Grande do Sul, que atrai milhares de jovens de outras cidades do interior para estudar não apenas na Universidade Federal de Santa Maria (UFSM) como também em outras instituições privadas de ensino superior. A festa que ocorria quando aconteceu o incêndio na boate havia sido organizada por estudantes de diversos cursos da UFSM, visando arrecadar fundos para as futuras festividades de formaturas. Assim, a grande maioria dos frequentadores eram jovens universitários. 
Os relatos de sobreviventes e a perícia realizada no local confirmaram que o incêndio começou quando um integrante da banda Gurizada Fandangueira lançou um artefato pirotécnico durante a apresentação que atingiu a espuma utilizada para o revestimento acústico da boate. Após as faíscas do artefato pirotécnico terem atingido a espuma do teto, os integrantes da banda e os seguranças tentaram apagar o fogo. Porém, os extintores de incêndio estavam vazios e as tentativas de conter o foco do incêndio utilizando a água das garrafas que se encontravam no palco não foram eficazes. Em poucos segundos, uma fumaça densa e escura havia tomado conta do local, dificultando a visibilidade e a respiração de aproximadamente mil pessoas que se encontravam na festa.

De acordo com as investigações da Polícia Civil, a superlotação da boate, a queima da espuma altamente inflamável e tóxica, a falta de iluminação de segurança que indicasse a saída, a inexistência de saídas de emergência (a boate contava apenas com uma única porta de entrada e saída) foram determinantes para o desfecho trágico. Muitas pessoas foram pisoteadas, sofreram queimaduras e lesões no aparelho respiratório e a maioria das mortes teve como causa mortis asfixia por fumaça tóxica (cianeto).

Nos dias e meses que se sucederam foram frequentes, tanto na mídia quanto nas conversas informais em diferentes lugares no cotidiano da cidade, os relatos sobre as dificuldades em lidar com as experiências de perda, luto e dor. Nas ruas, nas praças, nas casas, nas escolas, no comércio, ouviam-se comentários sobre os sentidos de injustiça e de incerteza do mundo, ou os desígnios do destino que arrebatara a vida de pessoas tão jovens; o drama de mães que perderam mais de um filho, ou o filho único; o horror das cenas de morte presenciadas em frente à boate e no Centro Desportivo Municipal (CDM) para onde foram levados os corpos para reconhecimento; as queimaduras e o precário estado de saúde de sobreviventes que permaneciam nos hospitais. Também se comentava sobre as buscas por atendimento nos serviços de saúde e usos de medicamentos, sobre o apelo às práticas religiosas e espirituais, e sobre o engajamento de familiares em movimentos políticos.

O presente artigo tem como ponto de partida o incêndio da boate Kiss e visa refletir sobre desdobramentos pessoais e coletivos da "tragédia" e so- 
bre "o que está em jogo" para aqueles que tiveram suas vidas profundamente afetadas por esse evento dramático. (KLEINMAN; KLEINMAN, 1995; DAS, 1999; DAS; KLEINMAN, 2001). Os dados aqui referidos fazem parte de uma pesquisa maior sobre "dor" e "sofrimento" que vem sendo desenvolvida pelas autoras desde janeiro de 2013 na cidade de Santa Maria, RS.

Parece oportuno recordar nessa introdução que o debate antropológico sobre "sofrimento" tem se pautado pela ideia de que emoções e sentimentos - sejam eles de felicidade ou pesar, bem como toda a gama de possibilidades que se coloca entre estes dois extremos - mesmo quando vividos individualmente, são delimitados por contextos sociais que lhes fornecem forma, sentido e razão. Não existe, portanto, nessa perspectiva, definição única de "sofrimento" tampouco uma forma de "sofrimento" que seja universal. Entendemos que diferentes sociedades experienciam diferentes tipos de "sofrimento", de mal-estar, de aflição, de "dor", de desgosto profundo em diferentes tempos, e que estes são sempre mediados por condicionantes sociais e culturais. Como, e se, essas experiências sociais são corporificadas e significadas constitui-se como problema de pesquisa que remete a diferentes possibilidades. Por essa razão, fazemos uso do termo entre aspas no presente artigo.

Mais particularmente sobre o tema do "sofrimento", existe no Brasil um debate que acompanha a formação do campo da Antropologia do Corpo e da Saúde no país. Nessa tradição, ressalta-se a dimensão físico-moral das diferentes formas de mal-estar, a qual abre caminho para uma abrangente relativização da própria noção de “sofrimento". Neste contexto de debate, Luís Fernando Dias Duarte $(1993,1994,1998)$ sugere a recuperação da categoria "perturbação" para referir doenças e sofrimentos lembrando que:

Muitas das situações reconhecidas como "patológicas" em nossa cultura - pelo menos em suas versões mais eruditas ou oficiais - podem ser consideradas "regulares" em outras, deixando mesmo de implicar qualquer "sofrimento peculiar" (DUARTE, 1998, p. 13).

O que importa, segundo essa perspectiva, não é partir ou chegar a uma definição de "sofrimento", mas compreender de que maneira o termo se asso- 
cia aos diferentes contextos sociais e políticos; não somente o que ele traduz, mas principalmente o que ele é capaz de produzir, quando evocado em situações específicas. Nesse sentido, não há intenção aqui de explorar o significado íntimo da dor e do sofrimento diante do evento dramático pesquisado, tendo em vista precisamente a valorização da sua dimensão pragmática e performativa (ABU-LUGHOD; LUTZ, 1990; COELHO; REZENDE, 2011)².

Tal como a presente pesquisa, outros estudos antropológicos realizados no Brasil sobre o tema do "sofrimento" relacionados a eventos dramáticos, tais como a de Fábio Araújo sobre o "Caso Acari” (ARAÚJO, 2008), a de Jurema Brites e Cláudia Fonseca sobre o projeto Mulheres da Paz (BRITES; FONSECA, 2013), a de Adriana Vianna e Juliana Farias (VIANNA; FARIAS, 2011) sobre o protagonismo simbólico da "mãe" de vítima de violência policial e a de Paula Lacerda sobre os meninos emasculados de Altamira (LACERDA, 2014, 2015), inscrevem-se, de maneira mais ou menos explícita, na linha teórico-conceitual de Veena Das. Além dessa inspiração teórica, a revisão desses trabalhos demostra que eles compartilham também dos mesmos dilemas de pesquisar contextos de sofrimento e violência. Isso foi expresso por Vianna e Farias, referindo-se à sua pesquisa "A Guerra das Mães" da seguinte maneira:

Durante o acompanhamento desses percursos, marcados por tantos enfrentamentos, sofrimentos, recuos, posicionamentos, silêncios, discursos, passeatas, vigílias, premonições, sonhos, orações e julgamentos, talvez o que se revele como mais desafiador a ser observado seja a competência dessas mulheres e homens para se moverem nesse duplo limite político da perda pessoal e da ação coletiva, dos vivos e dos mortos, da contenção e do desvario, do cotidiano e do extraordinário (VIANNA; FARIAS, 2011, p. 112).

Não se trata de generalizar as abordagens específicas das pesquisas supracitadas, mas de destacar a potência do pensamento da antropóloga indiana para compreender e interpretar esses fenômenos no Brasil.

\footnotetext{
A discussão das dimensões pragmáticas, performáticas e estéticas de manifestações públicas na cidade de Santa Maria a partir da Antropologia das Emoções foi apresentada em outro artigo da nossa autoria, ver Siqueira e Victora (2017).
} 
Paralelamente a essa escolha, o presente artigo originou-se de uma aproximação com uma literatura de língua inglesa sobre o tema, que destaca as dimensões sociais, políticas e econômicas do mal-estar e da aflição. (KLEINMAN; DAS; LOCK, 1997). Interessa-nos aqui considerar as múltiplas relações daquilo que é experienciado pelos sujeitos como "luto", "dor", "sofrimento", doença e morte, com os processos sociais, políticos, econômicos, éticos e legais que estão envolvidos naquele infeliz acontecimento. Trata-se menos de considerar os processos sociais que produzem e são produzidos por, e sim em contextos de "sofrimento". Como a vida social e individual continua após ter sido severamente marcada por uma tragédia? Pegamos carona em problematizações apresentadas por Das $(2000,2007)$ e Das e Kleinman (2001) para perguntar: como se "habita um mundo" destroçado pela "dor" e pelo "sofrimento"? Como o acontecimento adentra a vida cotidiana? Como as comunidades produzem novos termos de consensos, dissensos, rupturas e reconstruções a partir de paradigmas rompidos? Nesse processo temos também perguntado sobre a apropriação política do "sofrimento" e sobre a medicalização das emoções. Essas foram as questões de partida da pesquisa que originou o presente artigo. Perguntas que evidentemente não podem ser respondidas nesse espaço, mas que inspiram as reflexões aqui desenvolvidas.

\section{NA SEQUÊNCIA DA TRAGÉDIA: METODOLOGIA, ÉTICA, JUSTIFICATIVA E CONCEITOS REVISITADOS}

O desenvolvimento de pesquisas em contextos de tragédias nas quais se verificaram perdas irreversíveis de vidas apresenta desafios de ordem metodológica e ética próprios. Assim como em outros eventos dramáticos de grandes proporções, o incêndio da boate Kiss despertou imenso interesse público e midiático com enfoque em diferentes aspectos - desde a investigação policial de identificação dos possíveis culpados pela tragédia até questões muito íntimas das personalidades das vítimas primárias ou secundárias assim reconhecidas em diferentes momentos. Um conjunto de familiares das vítimas foi re- 
petidamente entrevistado por veículos de comunicação, tendo alguns se tornado um tipo de personagem de um filme de terror, que se movimentando na trilha do luto pelas vidas perdidas, tinham como enredo principal a denúncia da impunidade dos culpados pela tragédia. Nesse cenário midiatizado consideramos eticamente impróprio nós também abordarmos as famílias para fins de pesquisa logo após o ocorrido, tendo em vista que nossas aproximações inevitavelmente revisitariam questões que já estavam sendo exploradas em excesso pela mídia ${ }^{2}$. Diante dessa preocupação decidimos adiar pelo menos por mais de dois anos a realização de entrevistas para a pesquisa, centrando a coleta de dados inicialmente em eventos e manifestações públicas promovidas pela Associação dos Familiares de Vítimas da Tragédia de Santa Maria (AVTSM) e outros movimentos como o Movimento Santa Maria Do Luto à Luta 3 .

Além do acompanhamento dos eventos públicos, desde o dia do incêndio coletamos as matérias, reportagens e imagens divulgadas na imprensa local e nacional a respeito das investigações, do inquérito, da criação dos movimentos de familiares, das manifestações públicas, do sofrimento de familiares e sobreviventes. Com este vasto material compomos um banco de dados com centenas de reportagens que nos possibilitam pensar sobre as repercussões da "tragédia".

Em agosto de 2015, portanto dois anos e meio depois do acontecimento, começamos a conversar com um grupo de pais que haviam publicado um livro com cartas psicografadas dos filhos que haviam morrido no incêndio da boate. A convite deles temos acompanhado o grupo em viagens, encontros informais e atendimento a sessões em centros espíritas kardecistas em diferentes cidades de São Paulo, Minas Gerais e Rio Grande do Sul. O encontro com essas famílias se deu inicialmente a partir do nosso interesse em conhecer as

\footnotetext{
Esta preocupação foi motivada pela reflexão apresentada por Kleinman e Kleinman (1995) sobre a "apropriação profissional do sofrimento", ou seja, sobre como diferentes campos do conhecimento se aproximam e transformam infortúnios e aflições das pessoas, seja com o intuito de divulgar (jornalismo), de pesquisar (ciências humanas) ou de tratar (medicina, psicologia).

3 Outros movimentos se formaram após a "tragédia”, como o Movimento Mães de Janeiro e a ONG Para Sempre Cinderelas. Alguns grupos passaram a se organizar também pela Internet, entre eles, Kiss: Que não se repita; Força aos Pais e Vítimas da Tragédia da Boate Kiss; Somos Todos Santa Maria - Não ao Esquecimento; Voltaremos a sorrir após haver justiça.
} 
circunstâncias de produção do livro "Nossa Nova Caminhada: psicografias de sete jovens que desencarnaram na boate Kiss em janeiro de 2013 em Santa Maria, Rio Grande do Sul", contendo as primeiras cartas psicografadas recebidas por familiares de pessoas que faleceram no incêndio. Os dados coletados nas sessões de psicografia, em encontros informais, entrevistas em profundidades e debates com estas famílias foram registrados em diário de campo das pesquisadoras, além de gravações em vídeo e/ou áudio. Todas as informações, inclusive nomes e circunstâncias citadas nesse texto a respeito deste grupo, foram autorizadas pelos interlocutores dessa pesquisa.

Pesquisar sobre a vida depois da tragédia nos colocou com frequência diante da pergunta sobre como as pessoas afetadas pelo luto suportam conviver com a dor da perda, sendo que muitas vezes fomos interpeladas pela noção de "resiliência", um conceito que, apesar de ter surgido em outra área do conhecimento, tem sido amplamente usado nas Ciências Humanas para se referir a capacidades e estratégias de indivíduos e grupos de superar adversidades. A representação imagética da resiliência em sites na internet reforça a ideia de elasticidade de corpos que retornam à forma original após terem sofrido pressão, compressão ou alongamento por forças externas. São ilustrativas as imagens de flores solitárias e de finos ramos verdes que desafiam a aridez de rachaduras no asfalto, ou a terra fraturada pela seca, mantendo-se vivas num cenário de desolação; ou árvores inclinadas pelo vento que se dobram, mas não quebram. Elas indicam com isso uma persistência sutil, uma habilidade de recuperação, uma resistência diante do infortúnio. Mas, em que pese o fato de que essas imagens expressem de forma significativa a fragilidade da vida diante de penosas realidades, ficamos nos questionando se esta versão "preto no branco" dava conta das matizes que encontramos no trabalho de campo.

Em seu livro Affliction, Das (2015) apresenta uma questão interessante para o presente estudo, a partir da observação de que em situações adversas,

Muitas pessoas dentro do mesmo ambiente movem-se entre dois limites da vida, um marcado pela desolação, e outro no qual são capazes de se envolver com outras pessoas, rir, comer, fazer sexo, cuidar de crianças, saudar os visitantes. (DAS, 2015, p. 2, tradução nossa). 
Diante disso, a pergunta que lhe parece mais pertinente não é sobre a resiliência das pessoas diante de eventos traumáticos, e sim sobre como as pessoas se movimentam entre estes dois limiares. Muito cedo no trabalho de campo percebemos que entre altos e baixos, dias melhores e dias em que mal se consegue levantar da cama, a vida das pessoas atingidas pela "tragédia" vai lentamente retomando o passo, adquirindo um novo ritmo pautado, na maioria das vezes, por fatores alheios às vontades ou capacidades individuais. É nesse sentido que a pesquisa antropológica se justifica. Com o foco nos espaços e formas de significação disponíveis no repertório de possibilidades no contexto da tragédia, esta pesquisa seguiu alguns caminhos de continuidade e ressignificação da vida.

Além disso, a ideia de resiliência como uma capacidade de superar problemas e resistir a pressões de diferentes ordens, indica a autora supracitada, pode pressupor que existem condições objetivas, como "as instituições", "o mercado", "a família", que produzem tensões, ou emoções, que afetam subjetividades individuais, com capacidades, ou intencionalidades, de resilir, ou não. Diferentemente, as perguntas de Das (2015) vão no sentido de superar a distinção entre condições objetivas que causam sofrimento por um lado e, por outro, subjetividades que surgem em decorrência dessas. Isso porque não seria adequado, ou possível, parear de forma direta processos institucionais com condições objetivas, nem experiência com processos de subjetificação. No caso de pesquisas que encontrem esses dilemas, é importante atentar para o fato de que os processos institucionais não são necessariamente objetivos; e tampouco a experiência é uma categoria transparente possível de ser compreendida como se fosse um objeto dado ao conhecimento. Existem muitas mediações possíveis, e necessárias, para que esses "pares" sejam conjugados. Concordando com a reflexão da autora, o presente artigo vai explorar aspectos da interpenetração de realidades nada objetivas com subjetividades em permanente reconstrução.

Analisamos aqui dois espaços sociais de reconstrução do mundo. O primeiro é o movimento político; a "luta por justiça" e pela "punição dos culpados" pela tragédia que teve origem no descaso de pessoas e instituições res- 
ponsáveis pela segurança do local se apresentaram como veículos de reorganização da vida daqueles que hoje convivem com o luto. O segundo é a espiritualidade, mais especificamente a doutrina espírita kardecista, na qual os significados do acontecimento, sua relação com o evento e com outros agentes envolvidos são modelados por aquilo que consideram ser os diferentes planos de existência humana e espiritual. ${ }^{4}$

\section{PARA QUE NUNCA MAIS ACONTEÇA...}

As manifestações públicas observadas ocorrem, em especial, no dia 27 de cada mês e, de acordo com os familiares que participam, têm como objetivo "manter viva a memória dos filhos", "lutar por justiça" e "para a tragédia não cair no esquecimento". Apesar de perceberem o agravamento de seu sofrimento a partir da relação com as instituições (prefeitura, câmara de vereadores, Ministério Público) ao lutarem por justiça, muitos familiares acabam por reorganizar suas vidas acompanhando o andamento do processo judicial, engajando-se nas atividades beneficentes propostas pelas associações de familiares e participando de manifestações públicas cujas bandeiras são: para que "não se repita" e para que "os responsáveis paguem" pela "tragédia" que causaram a tantas famílias.

A Associação de Familiares de Vítimas da Tragédia de Santa Maria (AVTSM) e o Movimento Santa Maria do Luto à Luta são organizações criadas cerca de um mês após o incêndio. A primeira envolveu-se inicialmente na assistência social às famílias de vítimas e em movimentos de reinvindicação por atendimento médico e psicológico aos sobreviventes, familiares e amigos, bem como promoção de atividades sociais e religiosas em datas significativas relativas à tragédia. O segundo adentrou, em certo sentido, um caminho mais politizado, sendo protagonista em protestos e movimentos reivindicatórios em

\footnotetext{
Outras pesquisas no Brasil e no exterior já têm discutido como vítimas de tragédias e seus familiares/amigos se organizam em associações e movimentos políticos de "luta por justiça" e de reinvindicação de direito à memória e à reparação. Entre elas: Silva $(2007,2010)$ sobre o desastre radioativo com o Césio-137 em Goiânia-GO; Zenobi (2010, 2013), a respeito do incêndio da Discoteca Cromañón em Buenos Aires, Argentina; Peixoto (2014) e Peixoto, Borges e Siqueira (2016), referentes ao incêndio da boate Kiss em Santa Maria, RS.
} 
espaços considerados relevantes por estarem relacionados ao incêndio ou às instituições que de algum modo estão envolvidas com a tragédia, tais como: o local onde está localizada a boate Kiss, a "tenda da vigília", a prefeitura, o Ministério Público, a Câmara de Vereadores da cidade.

Entendemos que as organizações de familiares que se constituíram em Santa Maria e as manifestações públicas realizadas nos meses seguintes ao incêndio foram fundamentais para que muitas pessoas atingidas direta ou indiretamente pela "tragédia" encontrassem formas de lidar com o sofrimento. As fissuras e as desordens no cotidiano dos atingidos, causados por acontecimentos dessa ordem, trazem consigo uma "luta diária" de reconstrução de si e também de outros sentidos que possibilitem a continuidade de suas vidas. Observa-se, através de relatos de familiares publicados na imprensa, que não raro eles apresentaram enorme dificuldade de retornarem às atividades laborais que exerciam antes da "tragédia". Assim, o engajamento nas associações e no movimento político se tornaram sua atividade principal, em certo sentido, sua razão para continuar vivendo. Em entrevista a uma revista local, um pai e uma mãe de vítimas falam sobre o cotidiano depois da morte dos filhos no incêndio e da participação nas organizações de familiares:

Abandonei a faculdade, minha cabeça funciona 24 horas na associação. Posso estar em casa, mas estou pensando como procurar justiça. Eu vivia um mundo de ilusão. Não que achasse que tudo era lindo, tinha minhas reivindicações. Mas quando você entra no meio do bolo da Justiça, da Política e do Governo, aí você vê que se não rezar, não tomar alguns remédios, acaba cometendo coisa pior, como um suicídio (ALENCAR; GIRARD, 2014. Entrevista de Sérgio da Silva, AVTSM).

Eu não tenho orgulho nenhum de estar no lugar que eu estou. Daria tudo para ter minha vida normal do jeito que eu tinha, com a minha filha do meu lado. Não me arrumo para ir a entrevistas porque a questão não é a minha exposição. Como é a minha vida hoje? Existem pessoas que eu não consigo nem mais falar. Cada leitura de inquérito ou

\footnotetext{
A "tenda da vigília" foi montada em abril de 2013 na Praça Saldanha Marinho, principal área comercial da cidade, por iniciativa da AVTSM, como um espaço para realização de homenagens às vítimas e para a tragédia "não cair no esquecimento". Ao longo dos meses, foi se tornando cada vez mais um local de encontro de alguns familiares e ponto de concentração das caminhadas e protestos.
} 
documento é um parto, um sofrimento, porque cada vez que a gente tem que ler esses relatórios, é como tocar o dedo na ferida. Como se todo dia acontecesse o 27 de janeiro de novo. É muito dolorido (ALENCAR; GIRARD, 2014. Entrevista de Carina Mignon, Movimento Santa Maria do Luto à Luta).

Observa-se que a continuidade da vida após a tragédia se materializa na tensão entre a "dor" e o "sofrimento" e a luta por "justiça”. O mundo possível da sua sobrevivência - aquele que lhes afasta do suicídio - é, paradoxalmente, aquele que continuamente lhes inflige "dor" e "sofrimento", tendo em vista que os processos reivindicatórios e seus desdobramentos colocam o "dedo na ferida".

Diante da dor da perda e também da sensação de injustiça e impunidade, os familiares marcaram fortemente o dia 27 como um dia de lembrar-se de seus entes queridos e de lutar por justiça. Assim, nesses dias, a cidade presenciou caminhadas, protestos, vigílias, abraços coletivos, celebrações religiosas. A observação desses eventos públicos revela uma performance profundamente emocionada e emocionante, cujo sujeito e objeto é a dor coletiva representada por fitas, balões, corações, pombos, mudas de plantas/flores e, principalmente, pelo número 242 que se tornou a personificação das vítimas.

O aniversário de um ano da tragédia, descrito a seguir, agregou todos esses símbolos em um ato público que, como os demais, envolve protesto e homenagem num único movimento profundamente marcado pelas emoções:

Na noite do aniversário de um ano da tragédia, cerca de 600 pessoas se reuniram em frente à boate Kiss para uma vigília até as três horas da madrugada, horário de início do incêndio. Ao chegar ao local, um grupo de jovens iniciou a pintura de 242 silhuetas no asfalto. As pessoas observavam atentas as pinturas que aos poucos foram tomando toda a rua. Alguns choravam, outros relembravam episódios da "tragédia”, muitos permaneciam em silêncio. Durante a madrugada, os organizadores chamaram os familiares para acenderem 242 velas e fazerem uma oração. Um coração havia sido pintado em meio às silhuetas, em frente à boate, e as velas foram sendo acesas de modo a contornar o coração. A emoção aumentava na medida em que se aproximava a hora 
e alguns familiares precisaram ser atendidos pelos profissionais da Cruz Vermelha que acompanharam o evento.

Às três horas teve início o toque de sirenes, palmas, apitos e gritos de "Acorda Santa Maria" e "Justiça" que ecoaram pelo centro da cidade durante vários minutos. Erguendo faixas e cartazes, a multidão se dirigiu para outra rua, onde os representantes do Movimento Santa Maria do Luto à Luta, ao microfone, falaram sobre o andamento do processo judicial, expressaram sua revolta contra o descaso da Prefeitura e as ações do Ministério Público e relembraram os momentos difíceis que enfrentaram durante aquele ano. No final da tarde do mesmo dia, a AVTSM organizou um ato na praça que contava com apresentações artísticas (música e danças tradicionais gaúchas), o "minuto de barulho" e um culto ecumênico. Muitos familiares estavam presentes vestindo camisas com fotografias de seus entes queridos e segurando cartazes. Após as apresentações musicais e de dança, adolescentes de uma escola pública da cidade entregaram rosas às mães das vítimas. Às seis horas da noite, além do toque dos sinos das igrejas e as palmas dos presentes em memória das vítimas, houve mais uma homenagem: a leitura dos nomes completos dos 242 mortos e, após a leitura de cada nome, um tambor soou uma batida e todos aplaudiam a vítima citada. $\mathrm{O}$ ato foi finalizado com uma celebração religiosa.

Muitos abraços foram trocados, muitas lágrimas derramadas, muitas emoções evocadas e nesse processo se renovaram os sentidos de um viver que encontra sentido na própria desolação da perda combinada com a luta incessante contra a impunidade daqueles que entendem ser os responsáveis pela tragédia. Como uma luta política, ela só tem sentido se vivida coletivamente. Para além de seus filhos, parentes e amigos, as pessoas que perderam a vida são, no seu conjunto, 242 vítimas cujo drama coletivo informa a renovação da vida dos que ficaram.

\section{QUANDO TEM QUE ACONTECER...}

O recurso ao movimento social e político por “justiça”, entretanto, não foi o caminho escolhido por muitos dos pais e familiares que, por diferen- 
tes razões, não compartilhavam das mesmas ideias e tampouco encontravam consolo no clamor por "justiça”. Como já referido anteriormente, ao longo da pesquisa viemos a conhecer um grupo de pais que já tinham alguma proximidade, ou que a partir do incêndio na boate procuraram a doutrina espírita para encontrar um sentido para as perdas sofridas. Isso não significa dizer que os pais, parentes e amigos que se envolveram na luta política não tivessem recorrido às religiões, ou mais amplamente à espiritualidade, para lidar com o sofrimento. Temos conhecimento de vários pais que trabalham ativamente no movimento político e que também frequentam assiduamente igrejas de diversas denominações, bem como de encontros e palestras relacionadas à doutrina espírita.

Entretanto, gostaríamos de refletir sobre o espiritismo não como um recurso, mas como uma forma de vida a qual produz sentido e empresta possibilidade para o enfrentamento da dor da separação de entes queridos. Nossa aproximação à essa realidade se deu a partir de contato estabelecido com um grupo de pais de jovens que morreram no incêndio e que haviam publicado um livro com cartas dos filhos psicografadas por médiuns espíritas kardecistas. Com esse grupo de pais e outros seus conhecidos e amigos que compartilham dos saberes da doutrina, viajamos de ônibus e de carro para São Paulo, Minas Gerais e Rio Grande do Sul, visitando centros espíritas onde encontramos médiuns que psicografaram novas cartas de seus filhos ${ }^{6}$.

Segundo a doutrina espírita kardecista, as cartas psicografadas são mensagens de quem não se encontra mais no plano terreno, intermediadas por médiuns, para familiares, amigos ou conhecidos que aqui permanecem. As sessões são públicas e assistidas por dezenas, às vezes centenas, de pessoas que permanecem por várias horas sentadas em salões onde as psicografias vão ocorrer. Não existe um número definido de cartas a serem psicografadas em cada sessão, nem tempo definido para a duração das sessões. As que assistimos ti-

\footnotetext{
A peregrinação a centros espíritas em busca por cartas psicografadas por parte de pais de pessoas falecidas em acidentes ou por violência já tem sido registrada e discutida em trabalhos acadêmicos de Antropologia no Brasil, como o de Moreira (2013). Uma pesquisa particularmente interessante que discute, entre outras coisas, o uso de mensagens psicografadas como provas possíveis em julgamentos jurídicos é a de Pereira (2014).
} 
veram em média cinco horas de duração, nas quais eram psicografadas entre quinze e vinte cartas por sessão.

Observamos que as cartas psicografadas oferecem um conforto abrangente e contribuem para compreensão sobre os desígnios de um plano maior de existência, que tem como referência o espiritismo. Por meio das mensagens uma nova possibilidade de vida é apresentada: no plano espiritual os jovens escrevem que estão bem; não sentem dores; estudam; trabalham, reencontram familiares já "desencarnados"; aproximam-se de pessoas que também estavam na boate naquela noite; estabelecem novas relações de amizade e parentesco; e pedem que os pais façam o mesmo, pois "a vida continua".

Nessa perspectiva, a morte como finitude não existe. As pessoas estão sempre vivas porque a vida está no espírito, não no corpo. O corpo é apenas um invólucro, que comporta o espírito nos períodos de encarnação. Nesse sentido, o incêndio da boate foi um momento de desencarnação de 242 espíritos. Não pode ser considerada uma "tragédia", na medida em que a passagem para o plano espiritual é valorada muito positivamente. Tampouco o incêndio pode ser considerado um "acidente", porque isso significaria que não havia propósito divino por trás do acontecimento. Uma conversa entre interlocutoras dessa pesquisa durante a viagem que fizemos juntas é reveladora desse destino que colocou naquele lugar e naquele tempo as pessoas que "precisavam desencarnar".

No extrato da conversa que segue, duas mães, Ana e Adriana, nos contavam sobre seus filhos, Dani e Matheus, um casal de namorados que "desencarnaram" juntos e que permanecem juntos no outro plano, conforme relatos recebidos pelas cartas psicografadas. Elas nos contavam as circunstâncias que os levaram a ir à boate naquela noite:

Ana: [...] o Matheus foi à boate por dois motivos: Um, que a Dani acompanhava ele nos rodeios e ele não ia, não era muito chegado numa boate, mas como a festa era da turma dela ele disse: não, agora vou ter que ir senão vou perder a namorada. [Outro motivo] E aí teve um rodeio, ele laçou e tudo, e ela foi acompanhar ele. [...] Os amigos dele até disseram: "não tu não vai...., “....não sei porque tu tem que ir nessa 
boate", os guris já disseram pra ele. [Mas ele disse] Não. Tenho que ir porque senão a Dani ainda fica braba porque eu não acompanho ela. Vou perder a namorada...

Adriana: [Boate] nem era a dele. Nem era o chão dele...

Ana: Eles não iam muito, nem a Dani.

Adriana: Não. A Dani não era muito...

Ana: Quando as coisas têm que acontecer...

Adriana: Acontece.

Ana: É, vai se encaixando as pecinhas, né?

Adriana: É, eu digo assim, quanto tempo a espiritualidade demorou para reunir todos, pra unir todos...

Ana: todos...

Adriana: todos precisavam, né? Todos precisavam desencarnar, todos precisavam de um [estala os dedos] acorda, né? Porque [ainda] foram aqueles que se queimaram, que ficaram com uma sequela e coisa e tal... Ficaram e não desencarnaram, né? Aqueles que conseguiram sair, graças a Deus. E eu digo assim, oh, de coração aberto, eu não tenho inveja das mães que os filhos saíram. Sinceramente, eu não tenho. Sou tranquila com isso.

Ana: Eu também. Acho que eles se libertaram, né? A gente que tá começando a estudar o espiritismo, a gente sabe, né? Que, de repente, eles agora estão livres.

Esta forma de compreender o que se passou no dia 27 de janeiro destitui de sentido a lógica do movimento de "luta por justiça", na medida em que a relação causal subjacente ao pleito deixa de existir. Além de "não trazer os filhos de volta", como referiram algumas vezes, os agentes designados como "vilões" nos processos não são reconhecidos como tais, segundo a perspectiva espírita sobre o evento.

Isso não quer dizer que esses pais não sintam profundamente a falta de seus filhos, que não chorem de saudade, que não revivam com dor a perda da convivência, que não postem nas redes sociais (Facebook) e no grupo do WhatsApp fotos e mensagens com referência à angústia da distância. Entretanto, o que lhes move adiante é a certeza da continuidade da vida que a doutrina lhes oferece. 
As cartas nesse contexto apresentam vários elementos que ajudam a consolar. Observamos, entretanto, que não se trata de um alívio permanente do sofrimento. O consolo precisa ser renovado constantemente na medida em que não se trata de uma "solução" para um "problema". É como um exercício que para ser eficaz precisa ser praticado por agentes de várias ordens: os pais, os médiuns, os trabalhadores de casas espíritas, as próprias cartas. É nesse sentido que periodicamente são realizadas buscas pelas psicografias (e psicofonias). Isso foi explicitado para nós por uma das mães numa conversa sobre como se sentia nas viagens em busca de cartas. No extrato a seguir ela explica que além de receber carta do seu filho, ela prevê a possibilidade de repassar uma palavra que leve também alívio para o sofrimento de outra mãe:

Adriana: Eu volto renovada! Eu digo que tenho prazo de validade. O meu tava vencido. Tava precisando de uma viagem prá cá. Nossa, é muito bom voltar pra casa com uma mensagem, sabendo que estão bem, citando o nome de outros que estão ali. E os que não tem a oportunidade de se manifestar, mas que às vezes tem uma palavrinha ... daí tu liga para aquela mãe e conta. Aquela palavrinha faz todo o sentido, faz toda a diferença. Muda também [a vida de outra mãe]. É muito bom, bah, é muito bom!

Observa-se que a potência das mensagens está precisamente na sua capacidade de evocar as particularidades dos indivíduos. Nas cartas, os jovens se referem nominalmente a outros que estão com eles e fornecem detalhes muito particulares das situações vividas em conjunto com os pais, o que tem o propósito de dirimir qualquer dúvida sobre suas identidades.

Isso não quer dizer que os pais somente se regozijem com o recebimento de cartas dos seus filhos. Através da observação participante das sessões de psicografia constatamos a prevalência de um sentimento de que o mesmo aconteça para outros também. Nas palavras de uma das mães, Adriana:

Outra coisa, assim, independente de tu receber, tu torce pelo outro. Tu fica feliz pelo outro que recebeu. Como ele [refere-se a um palestrante] falou hoje: o dia que tu chorar pela carta do outro, tu vai saber porque tu tá ali. 
Os laços de amizade e solidariedade que se formaram nesse movimento de busca e recebimento de cartas psicografadas é tão importante para os participantes que eles não conseguem vislumbrar a continuidade da vida sem esses laços. Em diferentes situações observamos e conversamos com eles sobre uma nova "família" que se formou após o evento. Em particular, o grupo formado pelos pais dos sete jovens que participam mais intensamente desse movimento espírita, cuja dinâmica foi descrita para nós por Mariângela nos termos de um delicado equilíbrio: "A fragilidade de um é sustentada pela força do outro; a descrição de um ajuda o outro a medir as palavras”.

São, na sua perspectiva, "amigos de outra vida”. Mesmo lamentando, evidentemente, as circunstâncias que os aproximaram, valorizam a relação que estabeleceram após a "desencarnação" dos filhos. Nas palavras de Rose: "Foi uma tragédia horrível que juntou um amor incrível!”.

Entendemos que é esse "amor incrível" que possibilita o retorno à vida, assim como a produção de novos significados para o mundo vivido. Os novos significados encontram-se principalmente baseados na doutrina espírita, que prega o amor incondicional, a solidariedade e a prática da caridade como forma de vida. Estamos nos referindo, portanto, a um conjunto de fatores que possibilitaram a recuperação da vida que, embora, de acordo com seus relatos, jamais voltará a ser como era antes do evento, torna-se suportável.

Uma das reflexões de Das, sobre o cotidiano após eventos críticos, diz respeito ao tempo como agente na construção da subjetividade. Sua pergunta sobre o "trabalho do tempo na criação do sujeito" (DAS, 2007, p. 95) parece particularmente relevante no contexto estudado, mesmo que seus questionamentos tivessem em vista uma realidade totalmente diversa, na qual lhe interessava questões de memória e de como o "passado se torna presente nas nossas vidas", entre outras coisas (DAS, 2007, p. 99). No caso da nossa pesquisa, observamos que a perspectiva de eternidade da existência, ou seja, de um tempo de vida que não tem fim, fundante da doutrina espírita, oferece um espaço de ressignificação que trabalha as subjetividades dos adeptos que passam a operar com novas formas e sentidos para todas as relações humanas e não humanas. Parece que na medida em que a percepção de um tempo eterno é internaliza- 
da, que o alongamento e alargamento da vida são corporificados pelos sujeitos, a dor e o luto vão se acomodando em tempos e espaços mais pacificados.

Um dos aspectos que chamou muito a atenção durante a viagem que realizamos com o grupo é a mudança em suas formas de experienciar e de lidar com o sofrimento. Como se aos poucos fossem fazendo as pazes com um mundo com o qual estavam em guerra desde a tragédia. Observamos que algumas pessoas, que nos primeiros dias da excursão apresentavam o semblante marcado pela tristeza, a postura curvada, o andar arrastado, pessoas emudecidas pelo luto e pela dor, foram se transformando diante dos olhos de todos num movimento de retroalimentação da esperança e de renovação da vida. Nos últimos dias da viagem todos falavam alto, riam, brincavam, comentavam sobre as cartas recebidas, compartilhando entusiasmado contentamento. $\mathrm{O}$ acompanhamento de longa duração do grupo nos permite também observar claras mudanças nas maneiras de sentir e de agir que se processam ao longo dos meses e anos. "Ler", "estudar", "conversar com os filhos", "o poder da oração", "visualizar coisas em sonhos", "entender os sonhos", "participar das atividades no centro espírita”, são referidos como empreendimentos que possibilitam um novo entendimento que contribui para a sua recuperação. Em uma conversa conosco e com outras "mães" do grupo que acompanhamos - Adriana, Mariângela, Sílvia e Viviane - Márcia contou sobre como a solução de problemas domésticos, juntamente com a "sintonia" dos seus sentimentos em relação às cartas psicografadas, o estudo, a participação no centro espírita e o contato direto com médiuns compõem um "caminho" que lhe levam a "ter mais a paz":

Márcia: Esta questão que me preocupava muito estando mais controlada [referia-se aos cuidados com o pai idoso que estava obtendo com o auxílio de uma acompanhante] me ajuda com as outras. Então eu até comentei [...] que eu sentia que estava conseguindo ter mais paz. E aí o Marcelinho [um dos seus dois filhos que "desencarnou" por ocasião do incêndio da boate] vai lá e - pã - na carta, vai lá e escreve: "mãe, quando eu me aproximo de ti, sinto o pulsar do teu coração e sinto que tu estás mais em paz, eu fico feliz". Eu já estava sentindo isso antes, e ele escreveu isso. Então, olha a sintonia! A gente vai procurando os caminhos e vai achando [...] 
Mariângela: Tem todo um contexto de maturidade adquirido ao longo de muito tempo.

Márcia: Eu continuo estudando; o Marcelo [refere-se ao esposo] continua. A gente tem participado mais, tem conversado...

Mariângela: Mas assim, que bom que deu aquele ...

Viviane: Vocês vão ao centro [espírita]?

Márcia: Ahã.

Mariângela: Que bom, porque é visível, entendeu? Eu notei, fiquei muito feliz.

[Demais participantes da conversa concordam com gestos e sons].

Márcia: Ai, que bom, porque eu estou me sentindo melhor. Eu estava conversando com as gurias [refere-se a nós, antropólogas]: "Gurias, a ligação é incrível!” A gente tem uma ligação tão forte com os nossos filhos porque se a gente se sente assim, eu sinto, eu sinto que eles estão bem.

Adriana: Eu converso com a Dani, eu digo: filha se tu estiver bem e em paz, a mãe está bem e em paz. Fica bem que eu fico bem.

Como pode ser visto nesse diálogo, as cartas fazem parte de um contexto que é reforçado pelo estudo da literatura espírita, pela participação no centro espírita, pelas conversas com amigos, pelo contato mais próximo estabelecido com médiuns, o aprendizado de novos sentimentos que, em conjunto, contam com o tempo para produzirem novas sensibilidades. Por fim, entendemos que são estas sensibilidades aprimoradas que, por sua vez, retroalimentam o sentido da recuperação no universo kardecista pesquisado.

\section{CONSIDERAÇÕES FINAIS}

Dentre as questões que inspiraram a pesquisa que realizamos, ressaltamos uma que condensa o problema dessa exposição, que diz respeito ao habitar um mundo destroçado pela dor e pelo sofrimento. Questão essa destacada por Das e Kleinman (2001) em suas reflexões sobre violência política e o impacto de acontecimentos traumáticos. Nos perguntamos pelos desdobra- 
mentos pessoais e coletivos da "Tragédia de Santa Maria" e sobre "o que está em jogo" para aqueles que tiveram suas vidas profundamente afetadas pelo incêndio da boate Kiss.

Sem pretensão de realizar comparações, esta pesquisa destacou dois caminhos diferentes percorridos por pais, parentes e amigos para conseguir conviver com a perda do mundo tal como o conheciam antes: um foi a via do movimento político de reivindicação por "justiça”; e o outro a via da espiritualidade. Isso não significa dizer que não haja trânsito entre um e outro, tampouco que não haja outras vias possíveis que não foram exploradas nessa exposição. Ao contrário, temos claras indicações de que muitas pessoas percorrem as duas vias, com maior ou menor intensidade, ao mesmo tempo, ou em momentos diferentes. Muitas outras recorrem também, ou somente, ao uso abrangente de medicações alopáticas e a diferentes tipos de terapias, o que não se conforma como uma contradição. Do ponto de vista antropológico, todas as formas são válidas e não seria possível, ou desejável, sugerir uma hierarquia entre as escolhas dos familiares das vítimas da tragédia.

Chama atenção nesses dois caminhos que a convivência com a dor se torna possível quando compartilhada por outros que viveram o mesmo drama. No caso do movimento por “justiça”, embora a manutenção de um estado de mobilização política permanente nos primeiros anos produzisse visível desgaste físico e emocional nos participantes, parece ser a convivência coletiva - mesmo com as frustrações do movimento - o que torna possível continuar vivendo. "O que está em jogo" para eles é a morte, que foi provocada por descaso e negligências de diversas ordens. Mas o que torna o jogo da vida suportável é o sofrimento compartilhado e sua expressão pública. Na nossa interpretação, o número 242 se tornou um ícone do movimento não apenas porque foi este o número de vítimas fatais, e sim porque é a imagem da magnitude da perda coletiva que dá sentido para o pleito político de identificação e punição dos culpados.

No caso do caminho da espiritualidade kardecista e seu encontro com as cartas psicografadas, o que está em jogo é a vida, que segundo essa perspectiva é eterna. O que separa os "encarnados" dos "desencarnados" são planos de 
existência os quais, de diferentes maneiras, proporcionam possibilidades para o aperfeiçoamento individual. A crença na doutrina espírita, que possibilita o recebimento de cartas pessoalizadas dos filhos que estão "do outro lado", produz um espaço de recuperação da vida "do lado de cá".

\section{REFERÊNCIAS}

1. ABU-LUGHOD, Lila; LUTZ, Catherine. Introduction: emotion, discourse and the politics of everyday life. In: LUTZ, Catherine; ABU-LUGHOD, Lila (ed.). Language and the politics of emotion: studies in emotion and social interaction. Cambridge: Cambridge University Press, 1990. p. 10-12.

2. ALENCAR, Atílio; GIRARD, Bibiano. Caso Kiss, um ano e quatro meses depois da tragédia. Revista O Viés. 2014. Disponível em: http://bit.ly/2u43Fm2. Acesso em: 21 fev. 2019.

3. ARAÚJO, Fabio A. Falta alguém na minha casa: desaparecimento, luto, maternidade e política. In: LIMA, Roberto Kant de (org.) Antropologia e direitos humanos V. Brasília: Booklink, 2008. p. 166-225.

4. BRITES, Jurema; FONSECA, Cláudia. As metamorfoses de um movimento social: Mães de vítimas de violência no Brasil. Análise Social, Lisboa, v. 48, n. 209, p. 858-877, 2013.

5. COELHO, Maria Claudia; REZENDE, Claudia. Introdução. O campo da antropologia das emoções. In: COELHO, Maria Claudia; REZENDE, Claudia (ed.). Cultura e sentimentos: ensaios em antropologia das emoções. Rio de Janeiro: Contracapa, 2011. p. 7-26.

6. DAS, Veena. Affliction: health, disease, poverty. New York: Fordham University Press, 2015.

7. DAS, Veena. Critical events: an anthropological perspective on contemporary India. New Deli: Oxford University Press, 1999.

8. DAS, Veena. Life in words: violence and the descent into the ordinary. Berkeley: University of California Press, 2007.

9. DAS, Veena. The act of witnessing. In: DAS, Veena et al. (org.). Violence and subjectivity. Berkeley: University of California Press, 2000. p. 205-225.

10. DAS, Veena; KLEINMAN, Arthur. Introduction. In: DAS, Veena et al. (org). Remaking a world: violence, social suffering, and recovery. Berkeley: University of California Press, 2001. p. 1-30. 
11. DUARTE, Luiz Fernando Dias. Os nervos e a antropologia médica norteamericana: uma revisão crítica. Physis, Rio de Janeiro, v. 3, n. 2, p. 43-93, 1993.

12. DUARTE, Luiz Fernando. A outra saúde: mental, psicossocial, físico-moral? In: ALVES, Paulo Cesar; MINAYO, Maria Cecília (ed.). Saúde e doença: um olhar antropológico. Rio de Janeiro: Fiocruz, 1994. p. 83-112.

13. DUARTE, Luiz Fernando; LEAL, Ondina (ed.). Doença, sofrimento e perturbação: perspectivas etnográficas. Rio de Janeiro: Fiocruz, 1998.

14. KLEINMAN, Arthur; KLEINMAN, Joan. Suffering and its professional transformation: toward and ethnography of interpersonal experience. In: KLEINMAN, Arthur. Writing at the margin. Berkeley: University of California Press, 1995. p. 95-119.

15. KLEINMAN, Arthur; DAS, Veena; LOCK, Margareth (ed.). Social suffering. Berkeley: University of California Press, 1997.

16. LACERDA, Paula. Meninos de Altamira: violência, "luta" política e administração pública. Rio de Janeiro: Garamond, 2015.

17. LACERDA, Paula. O sofrer, o narrar, o agir: dimensões da mobilização social de familiares de vítimas. Horizontes Antropológicos, Porto Alegre, ano 20, n. 42, p. 49-75, 2014.

18. MOREIRA, Patrícia C. Morte e luto nas linhas do além: as cartas psicografadas em Teresina. In: REUNIÃO EQUATORIAL DE ANTROPOLOGIA, 4.; REUNIÃO DE ANTROPÓlOGOS DO NORTE E NORDESTE, 13., 2013, Fortaleza. Anais... Fortaleza: UFC, 2013.

19. PEIXOTO, Priscila dos Santos. Acorda Santa Maria: estratégias coletivas de organização dos familiares das vítimas da boate Kiss. 2014. Dissertação (Mestrado em Ciências Sociais) - Universidade Federal de Santa Maria, Santa Maria, 2014.

20. PEIXOTO, Priscila dos Santos; BORGES, Zulmira Newlands; SIQUEIRA, Monalisa Dias de. A despedida anunciada: emoções e espiritualidade entre familiares das vítimas da Boate Kiss. Ciencias Sociales y Religión, Porto Alegre, v. 18, n. 24, p. 71-89, 2016. Disponível em: https://bit.ly/2MQcMPD. Acesso em: 19 abr. 2017.

21. PEREIRA, Amanda Gomes. Justiça na religião e conforto no sistema judiciário: relações político-religiosas entre familiares de Vítimas da violência urbana no Rio de Janeiro. Intratextos, Rio de Janeiro, v. 5, n. 1, p. 29-45, 2014.

22. SILVA, Telma Camargo. As celebrações, a memória traumática e os rituais de aniversário. Revista da UFG, Goiânia, n. 1, p. 12-18, ago. 2007.

23. SILVA, Telma Camargo. Eventos críticos: sobreviventes, narrativas, testemunhos e silêncios. In: REUNIÃO BRASILEIRA DE ANTROPOLOGIA, 27., 2010, Belém. Anais... Brasília: ABA, 2010. 
24. SIQUEIRA, Monalisa Dias de; VICTORA, Ceres. O corpo no espaço público: emoções e processos reivindicatórios no contexto da "Tragédia de Santa Maria". Sexualidad, Salud y Sociedad, Rio de Janeiro, n. 25, p. 166-190, 2017.

25. VIANNA, Adriana; FARIAS, Juliana. A guerra das mães: dor e política em situações de violência institucional. Cadernos Pagu, Campinas, n. 37, p. 79-116, jul.-dez. 2011.

26. ZENOBI, Diego. Los familiares de víctimas de Cromañón, en la encrucijada del 'dolor': emociones, relaciones sociales y contextos locales. RBSE, São Paulo, v. 9, n. 26, p. 581-627, 2010.

27. ZENOBI, Diego. Del 'dolor' a los 'desbordes violentos': un análisis etnográfico de las emociones en el movimiento Cromañón. Intersecciones en Antropología, Buenos Aires, v. 14, n. 2, p. 353-366, 2013. 